\title{
Evaluation of Oxidative Stress Biomarkers in Rat Heart Exposed to Diazinon and Vitamins $E$ and $C$
}

\author{
Tahmasebi K. ${ }^{1} M S c$, Jafari M.* PhD, Ahmadi A. ${ }^{2} M S c$
}

${ }^{*}$ Chemical Injuries Research Center, Baqiyatallah University of Medical Sciences, Tehran, Iran

1Biochemistry Department, Medicine Faculty, Baqiyatallah University of Medical Sciences, Tehran, Iran

${ }^{2}$ Students Research Center, Baqiyatallah University of Medical Sciences, Tehran, Iran

\begin{abstract} in rat heart. analysis of variance (ANOVA) followed by post hoc Tukey test. inhibited changing of these parameters. induced oxidative stress by scavenging free radicals.

\section{Keywords}

Diazinon [http://www.ncbi.nlm.nih.gov/mesh/68003976];

Vitamin E [http://www.ncbi.nlm.nih.gov/mesh/68014810];

Vitamin C [http://www.ncbi.nlm.nih.gov/mesh/68001205];

Oxidative Stress [http://www.ncbi.nlm.nih.gov/mesh/68018384];

Heart [http://www.ncbi.nlm.nih.gov/mesh/68006321];

Rat [http://www.ncbi.nlm.nih.gov/mesh/68051381]
\end{abstract}

Aims: Organophosphates such as diazinon (DZN) induce the production of free radicals and oxidative stress. The aim of this study was to evaluate the role of vitamins $\mathrm{E}$ and $\mathrm{C}$ as antioxidants in reduction of DZN-induced oxidative stress

Materials \& Methods: In present experimental study, 36 male Wistar rats were randomly divided into six groups; control (corn oil as DZN solvent), DZN $(100 \mathrm{mg} / \mathrm{kg})$, vitamin E $(150 \mathrm{mg} / \mathrm{kg})$, vitamin C $(200 \mathrm{mg} / \mathrm{kg})$, vitamin E+DZN and vitamin C+DZN. 24 hours after intraperitoneal injection, animals were anesthetized by ether, and heart tissue was quickly removed. After tissues hemogenation, superoxide dismutase (SOD), catalase (CAT), glutathione Stransferase (GST) and lactate dehydrogenase (LDH) activities, as well as glutathione (GSH) and malondialdehyde (MDA) levels were determined by biochemical methods. The data were statistically analyzed using Instat 3.3 by

Findings: DZN increased SOD, CAT and GST activities $(\mathrm{p}<0.01)$ and MDA level $(p<0.05)$, while decreased LDH activity $(p<0.05)$ and GSH content $(p<0.01)$ in heart compared with the control group. Administration of vitamins $\mathrm{E}$ and $\mathrm{C}$

Conclusion: Administration of vitamins $\mathrm{E}$ and $\mathrm{C}$ as antioxidant decreases DZN-

\footnotetext{
* Corresponding Author

Tel: +982122289942

Fax: +982126127281

Address: Biochemistry Department, Medicine Faculty, Baqiyatallah University of Medical Sciences, Araj Treeways, Artesh Boulevard, Tehran, Iran

m.jafari145@gmail.com

Received: November 12, $2014 \quad$ Accepted: February 14, 2015 ePublished: April 16, 2015
} 


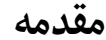

اركانوفسفرههاى حشرهك بله بلطور شايع در كشاورزى استفاده

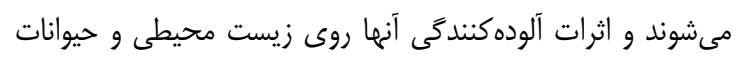

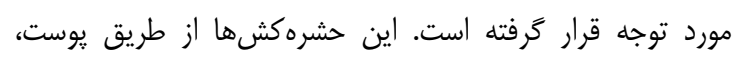

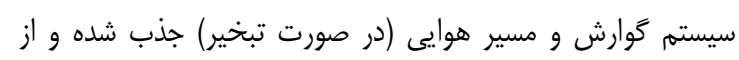

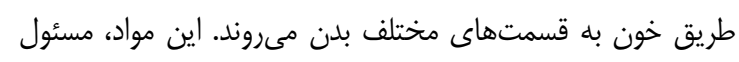

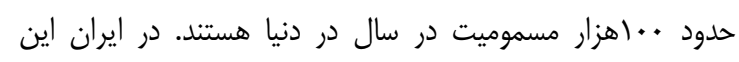
تركيبات يكى از علل مركَومير ناشى از مسموميت هستند. اثرات

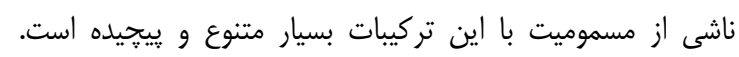

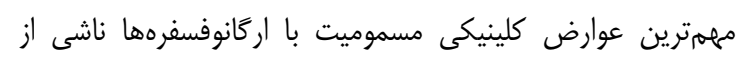

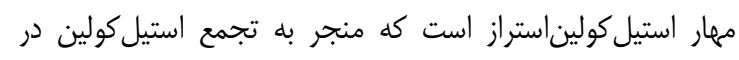

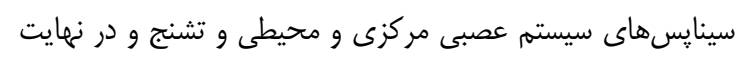

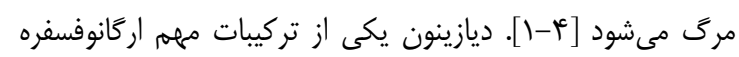

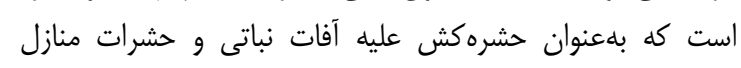

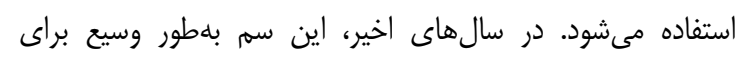

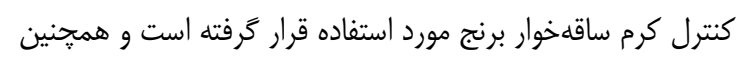

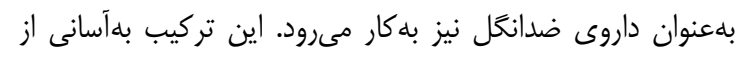

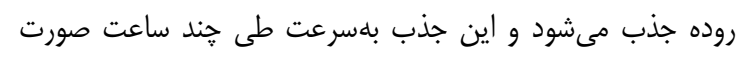

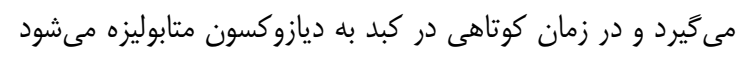

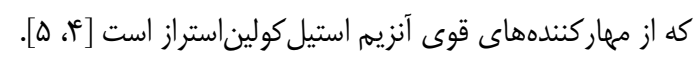

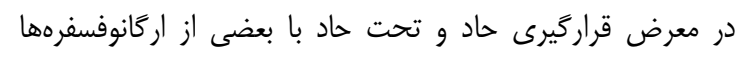

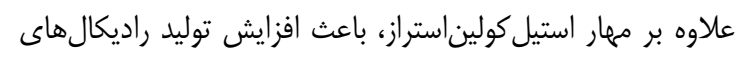

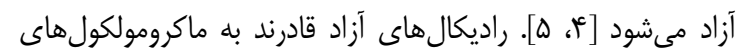

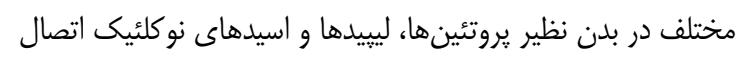

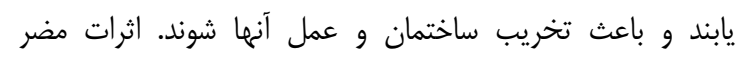

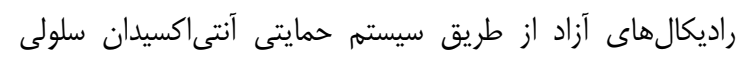

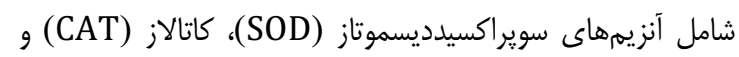
كلوتاتيون S- ترانسفراز (GST) و آنتى اكسيدان غيرآنزيمى مانيد (GST)

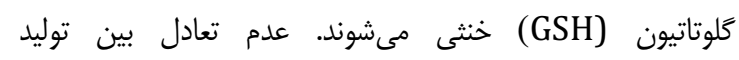

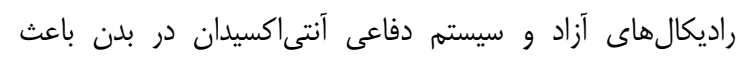

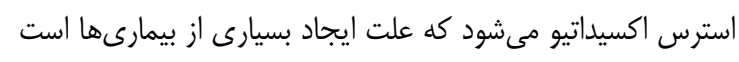

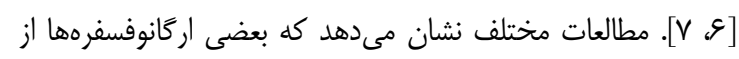

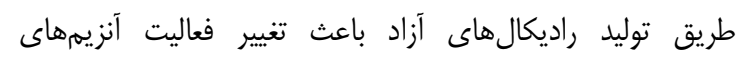

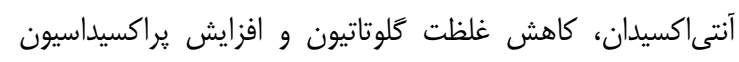

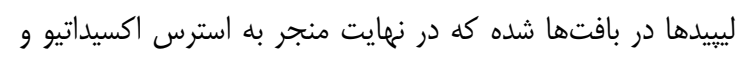

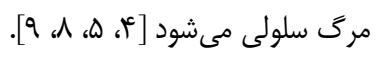
با توجه به تاثير اركانوفسفرهها روى سلو سيستم آنتىاكسيدان احتمالاً

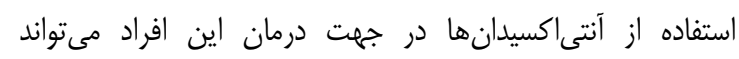

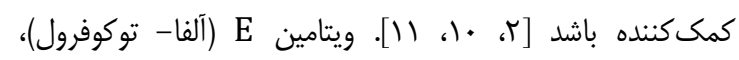

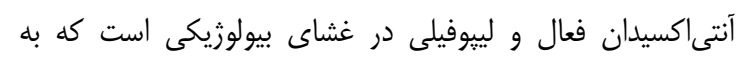

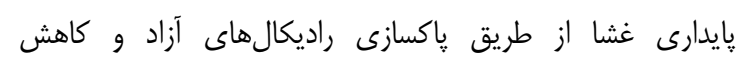
يراكسيداسيون ليييدها در غشا كمك مى كند. اين ويتامين در تمام آراد
ارزيابى شاخصهاى استرس اكسيداتيو در قلب

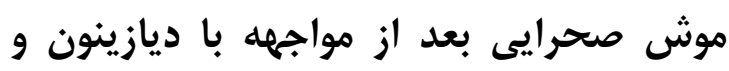

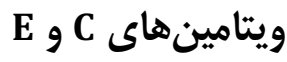

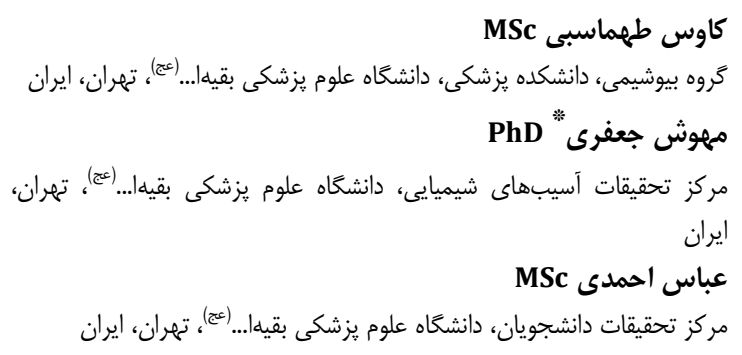
جكيده

اهداف: اركانوفسفرهها نظير ديازينون باعث القاى توليد راديكالهاى آزاد آنراد

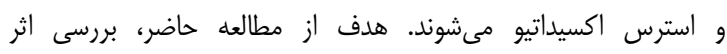

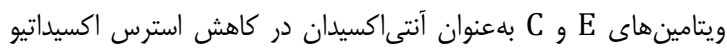

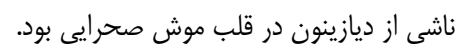

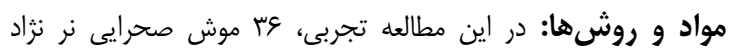

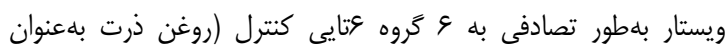

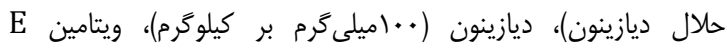

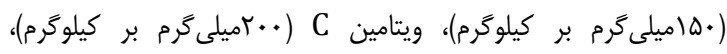

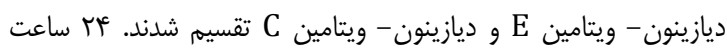

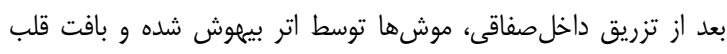

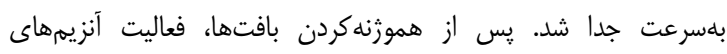

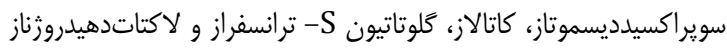

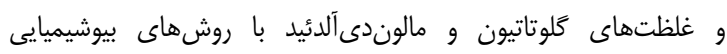

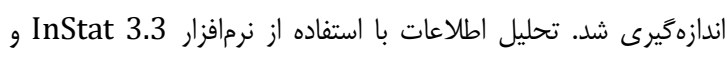
آزمون آناليز واريانس يكطرفه بهانهمراه آزمون تعقيبى توكى صورت

كرى كرت.

يافتهها: ديازينون باعث افزايش فعاليت آنزيمهاى سويراكسيدديسموتاز،

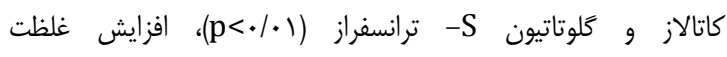

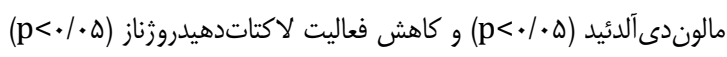

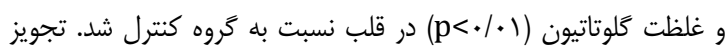

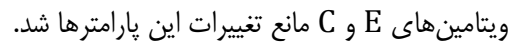

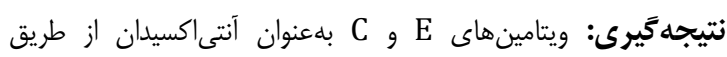

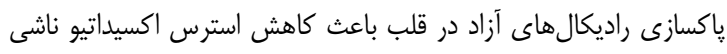

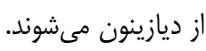
كليدوازهها: ديازينون؛ ويتامين E؛ ويتامين C؛ استرس اكسيداتيو؛ قلب؛ موش صحرايى

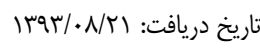

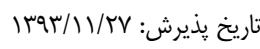
m.jafari145@gmail.com : تاريخ بذينده مسئول:

دوره اr، شماره ا، بهار Fraf

فصل نامه افق دانش 


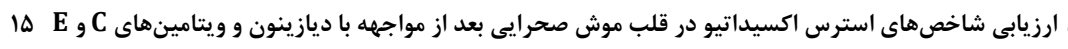

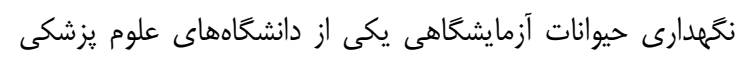

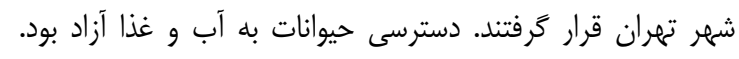

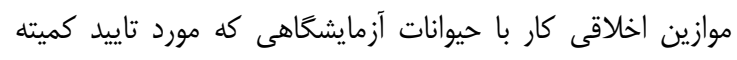

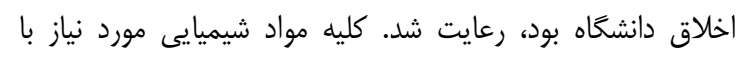

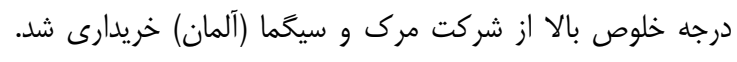

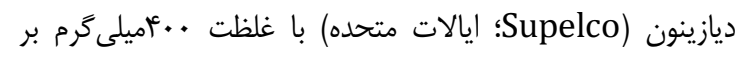

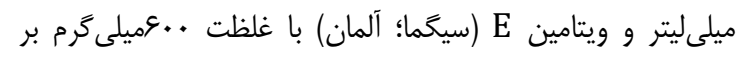

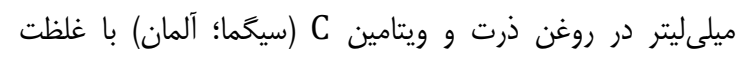

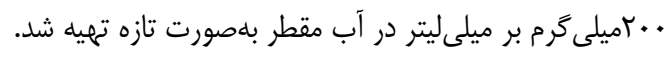

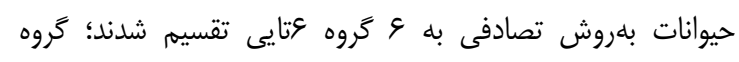

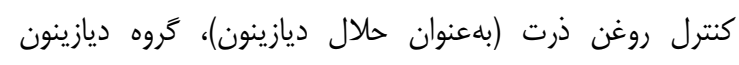

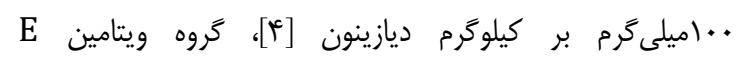

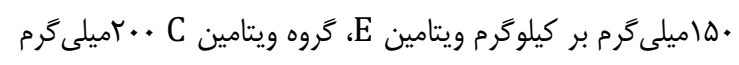

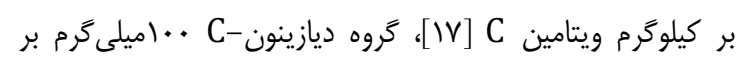

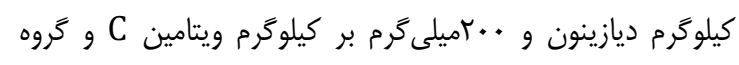

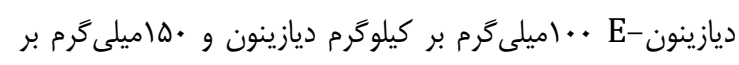

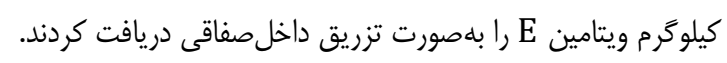

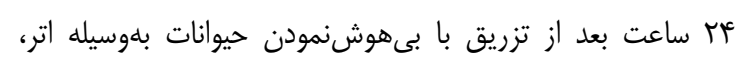

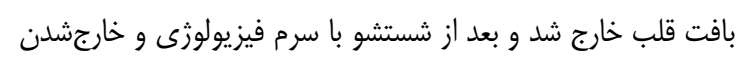

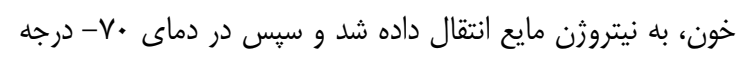

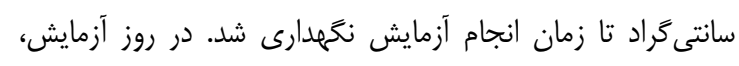

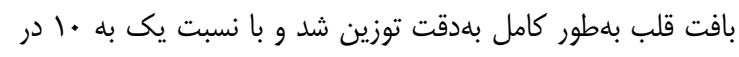

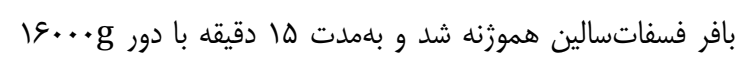

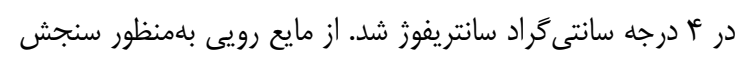
شاخصهاى مورد نظر استفاده شد.

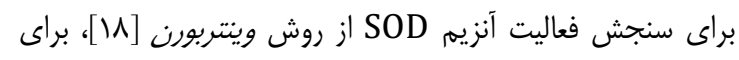

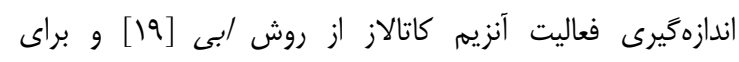

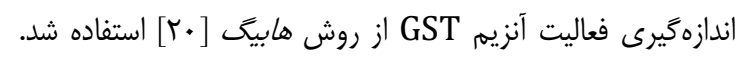

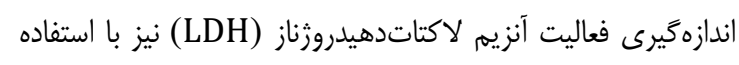

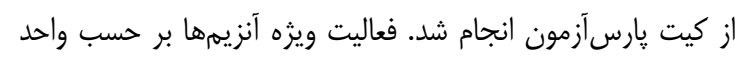

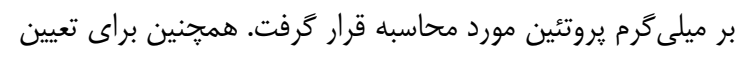

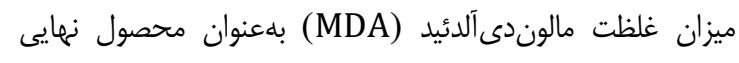

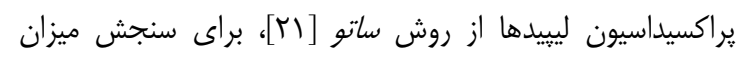

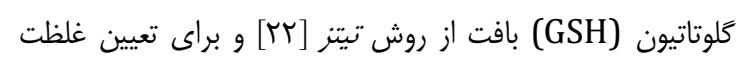

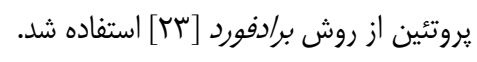

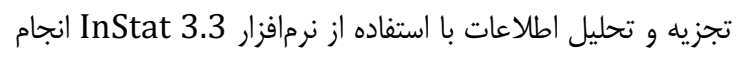

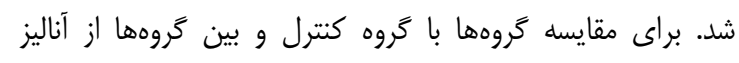
واريانس يكىرفه بههمراه آزمون توكى استفاده شد.

يافتهها

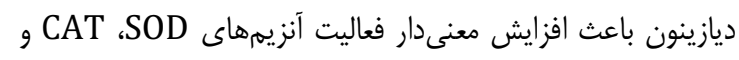
GST
بافتها انتشار مى يابد و در بافت جربى ذخيره مى شود. ويتامين E از از

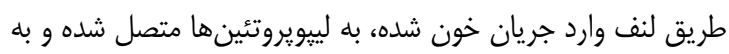

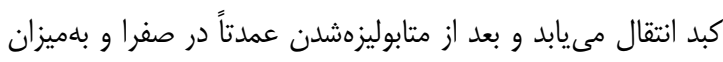

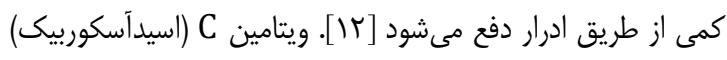

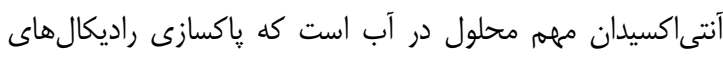

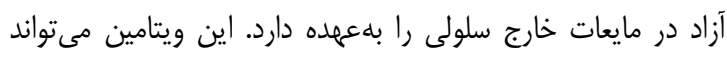

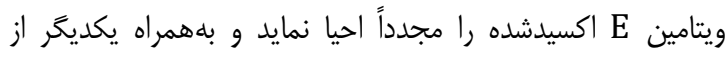

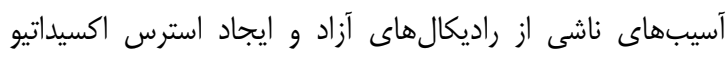

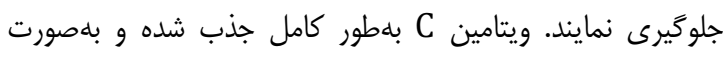

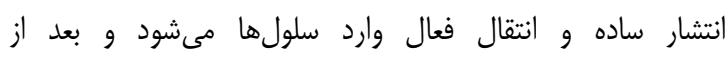

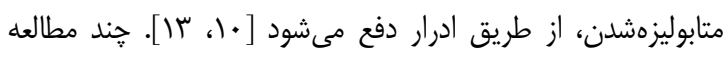

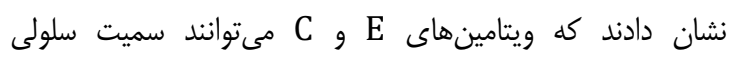

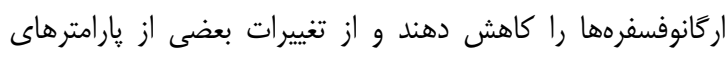

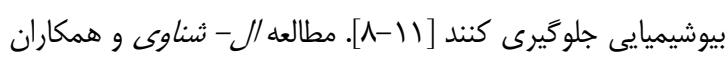

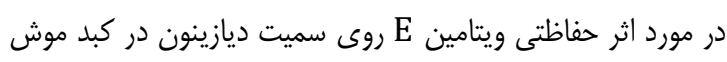

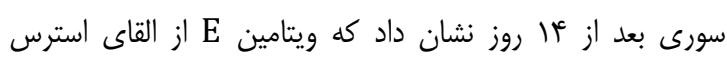

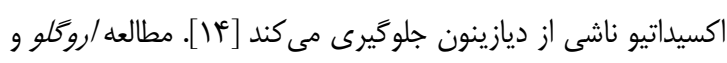

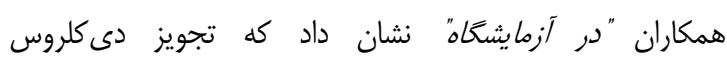
باعث كاهش فعاليت آنزيمهاى آنتىاكسيدان و آنسان

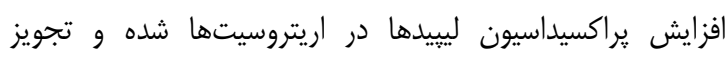

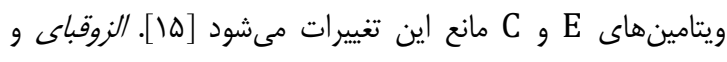

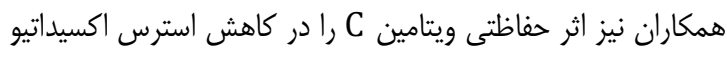

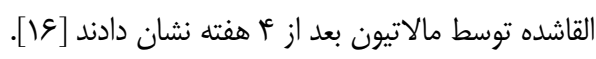

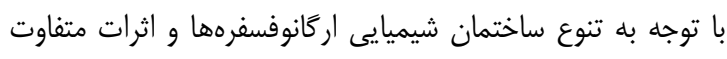

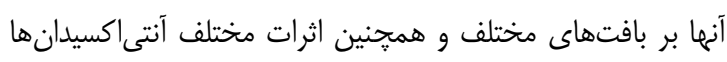

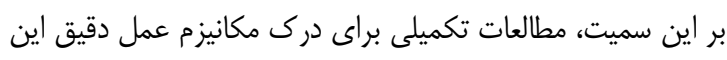

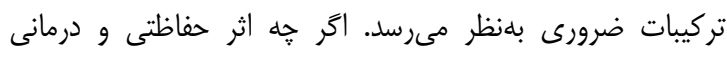

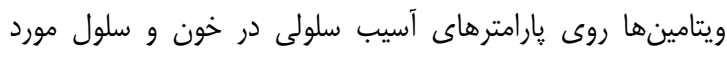

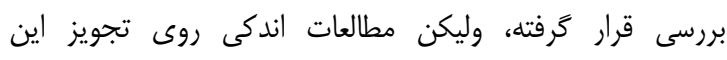

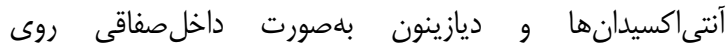

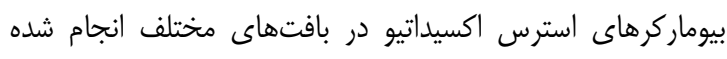

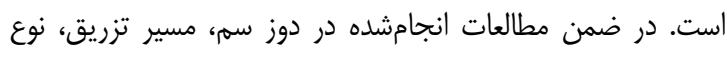

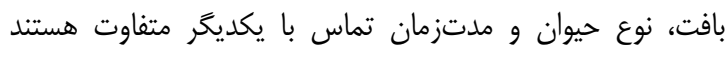

[1 [1-1)]

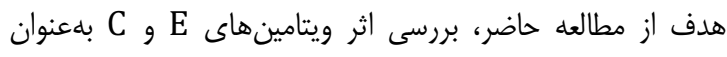

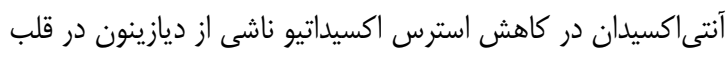
موش صحرايى با سنجش شاخصهاى استرس اكسيداتيو بود.

\section{مواد و روشها}

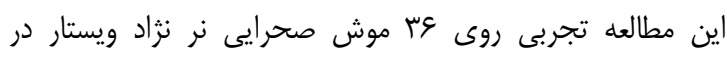

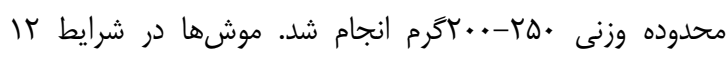

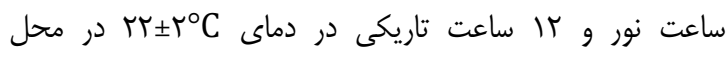


مقايسه با كروه ديازينون معنىدار نبود. همجنين ديازينون باعث كاهش معنى دار غلظت و افزايش معنى دار غلظت

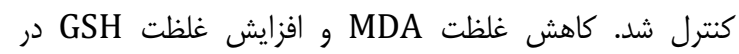

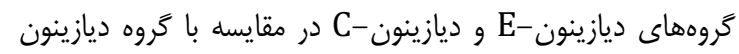

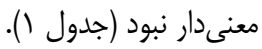

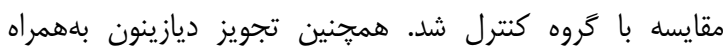

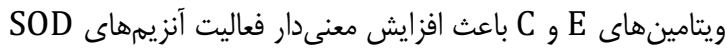

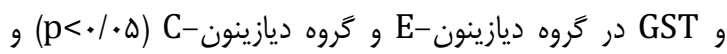

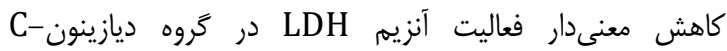

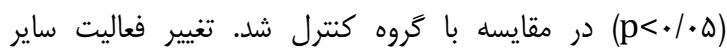

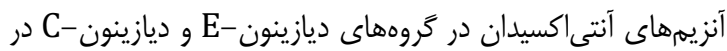

جدول () اثر ديازينون و ويتامينهاى E C Cبتنهايى و در تركيب با همه، بر فعاليت آنزيمهاى آنتىاكسيدان و غلظتهاى كلوتاتيون (GSH) و مالوندى آلدئيد (MDA) در

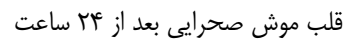

\begin{tabular}{|c|c|c|c|c|c|c|}
\hline $\begin{array}{c}\text { ديازينون } \\
\text { C- }\end{array}$ & 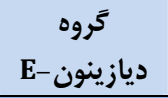 & $\begin{array}{c}\text { ويتامين C } \\
\text { C }\end{array}$ & ويتامين E & ديازينون & كنترل & 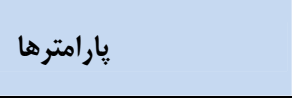 \\
\hline & & & & & \multicolumn{2}{|c|}{ آنزيمهاى آنتى اكسيدان (واحد بر ميلى كرم بروتئين) } \\
\hline$\kappa) / \Delta q \pm \psi / \Delta \Lambda^{*}$ & $r \tau / 9 T \pm r / 9 \Lambda^{*}$ & $r V / V \Delta \pm r / q \Delta$ & 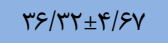 & $r \mu / M \pm \Gamma / N r^{* *}$ & $\Gamma \Psi / \backslash \Lambda \pm \digamma r / \Psi \Lambda$ & سويراكسيدديسموتاز \\
\hline$r V / \Delta Q \pm / / V t$ & $t R / t r \pm I / N E$ & $r r / \Lambda I \pm I / A V$ & $T F / \Delta \Delta \pm 1 / Q \Lambda$ & $r q / \kappa+ \pm 1 / q)^{* *}$ & $r F / \Lambda r \pm 1 / q 1$ & كاتالاز \\
\hline$\Delta V / \Delta q \pm \Gamma / \Lambda r^{*}$ & 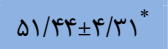 & $F) / \Delta \xi \pm r / F \Lambda$ & $\mu \varphi / / f \pm r / \| r$ & $\left.\Delta r / r \varepsilon_{ \pm} r / q\right)^{* *}$ & 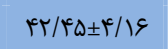 & كلوتاتيون S- ترانسفراز \\
\hline $1.9 / 1 T \pm 9 / r \Delta^{*}$ & $\| 1 T / 9 T \pm 1 r / r \pi$ & $|r / / \Delta q \pm| r / v r$ & $\mid m E / Q V \pm 1 \cdot / F \Delta$ & $1 \cdot N / \cdot 9 \pm 11 / \Delta r^{*}$ & ع & لاكتاتدهيدروزناز \\
\hline \multicolumn{7}{|c|}{ غلظتهاى كلوتاتيون و مالوندى آلدئيد (نانومول بر ميلى گرم بروتتئن) } \\
\hline$N / \wedge q \pm 1 / \cdot 9$ & $9 / 1 \varepsilon \pm 1 / \uparrow \varphi$ & $9 / 9 / \pm 1 / 10$ & $1 . / 4 F_{ \pm} \pm 1 / / f$ & $V / Q Y \pm \cdot / \Lambda \Delta^{* *}$ & $1 \cdot / 8 \mid \pm 1 / \cdot 1$ & كلوتاتيون \\
\hline $\mid 1 / 4 r \pm 1 / 4 q$ & $11 / r q \pm 1 / \cdot v$ & $9 / r \Delta \pm 1 / \cdot 1$ & $9 / \Delta \backslash \pm 1 / \cdot V$ & $11 / 9 \Lambda \pm 1 / \cdot r^{*}$ & $9 / V f_{ \pm} \pm / 99$ & مالوندى آلدئيد \\
\hline
\end{tabular}

اين اختلاف نتايج در مطالعات مختلف ناشى از نوع، نزاد و كَونه

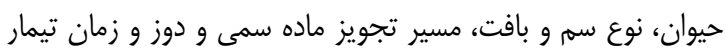
است. نتايج اين تحقيق موافق نتايج مطالعاتى است كه كه نشان

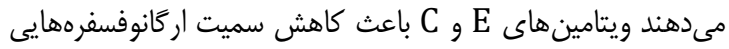

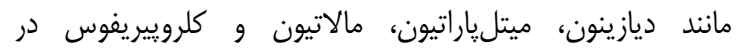

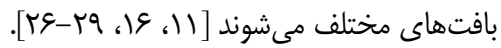

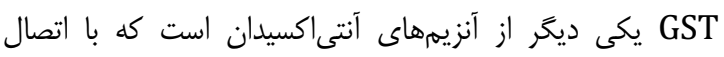

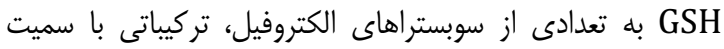

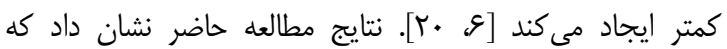
ديازينون سبب افزايش فعاليت GST در قلب موش صحرايى شده و

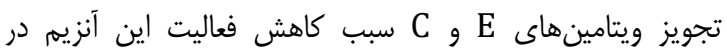

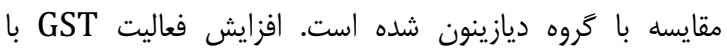

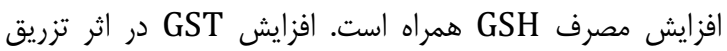
ديازينون نشاندهنده افزايش دفاع بدن در مقابل اين سم و دفر إنع

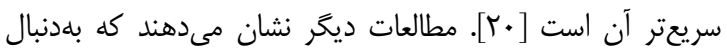

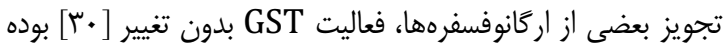

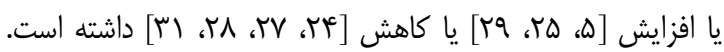

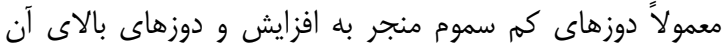

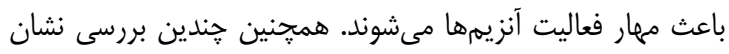

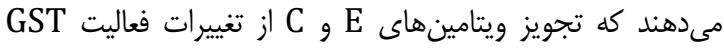

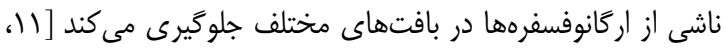

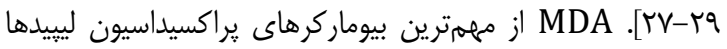

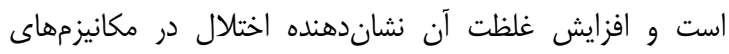

بافت قلب بلهورت يك يمب بلمنظور خونرسانى به ساير بافتها عمل مى كند. ماهيجه قلب نمى تواند اكسيثن را براى استفاده ذخيره

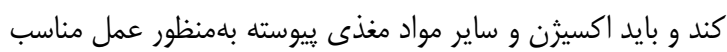

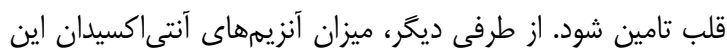

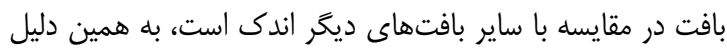

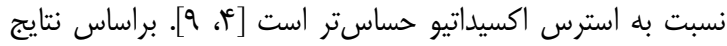
اين مطالعه، تجويز ديازينون باعث افزايش فعاليت آنزيمهاى

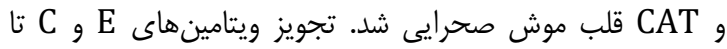

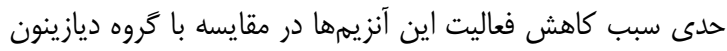

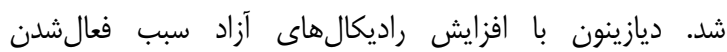

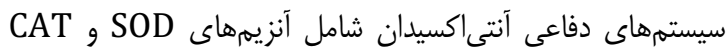
مىشود. افزايش فعاليت SOD در اين مطالعه باعث كاهش راديكال سويراكسيد و افزايش فعاليت آنزيم كاتالاز باعث خنثىشدن

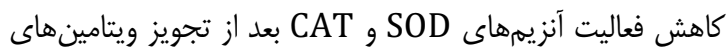

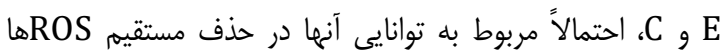

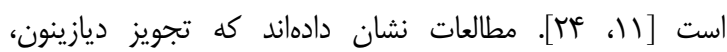
ياراكسون و ديمتوات (Dimethoate) موجب افزايش فعاليت

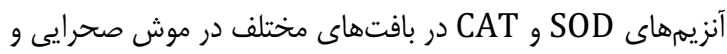

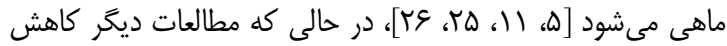

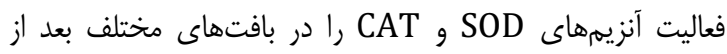

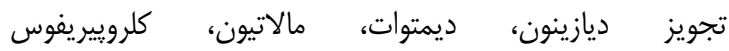
(Chlorpyrifos)

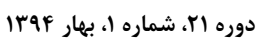
فصل نامه افق دانش 


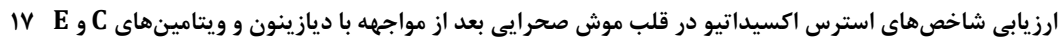

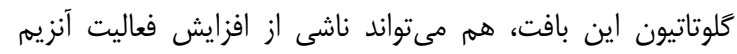
GST

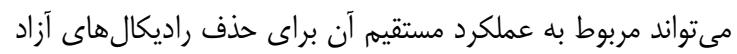

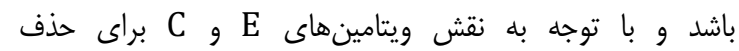

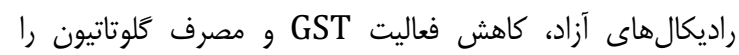

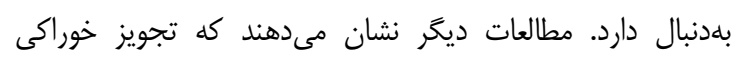

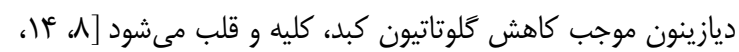

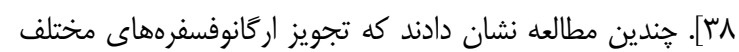

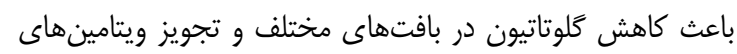

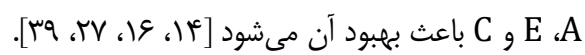

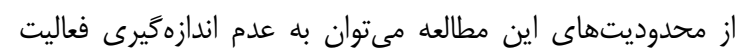

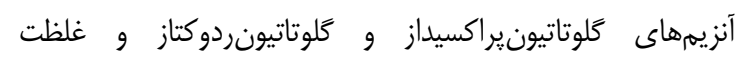
كلوتاتيون اكسيدشده اشاره كرد كه به دليل كمبود بودجه انجام نشد. در ضمن براى درى مكانيسم دقيق اثرات اركانوفسفرهها و ويتامينهاى E و C ي يشنهاد مى شود كه بيان ثن آنزيمهاى سيستم

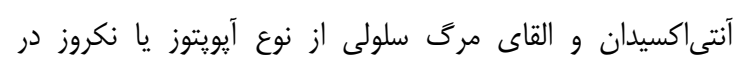
بافتهاى مختلف بررسى شود.

\section{نتيجه كَيرى}

ديازينون با توليد راديكالهاى آزاد و تغيير فعاليت آنزيمهاى أنتىاكسيدان و افزايش تيراكسيداسيون ليييدهاى غشا و و كاهش

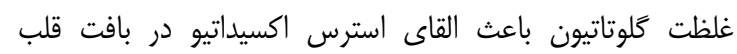

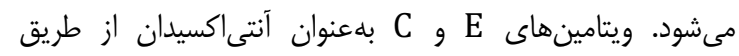
ֶاكسازى راديكالهاى آزاد باعث كاهش استرس اكسيداتيو ناشى از

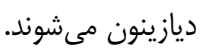

تشكر و قدردانى: نويسندكان بر خود لازم مىدانند از مريمر

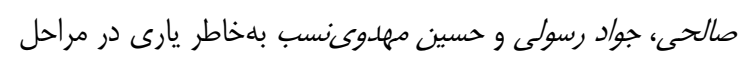

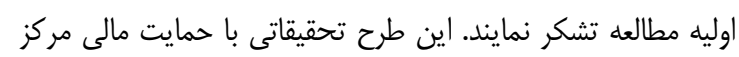

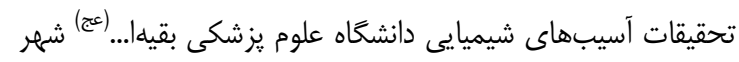

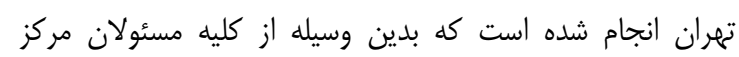
مربوطه تشكر و قدردانى مى شود.

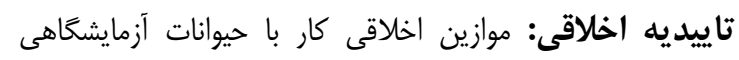

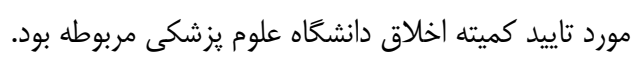
تعارض منافع: تعارض منافع در اين مقاله وجود ندارد.

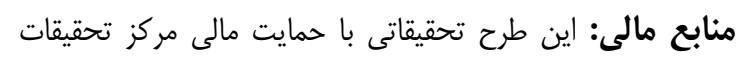

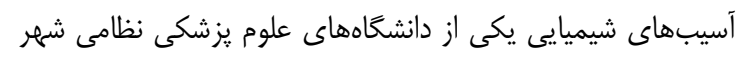

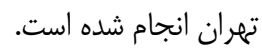

منابع

1- Baconi DL, Bârcă M, Manda G, Ciobanu AM, Bălălău C. Investigation of the toxicity of some organophosphorus
دفاعى آنتى اكسيدانهاى غيرآنزيمى و آنزيمى است [بس]. در مطالعه

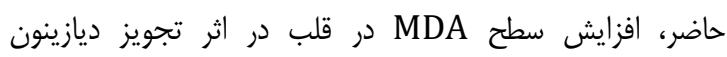

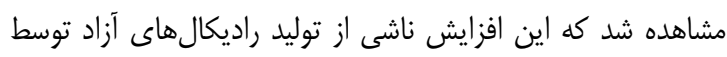

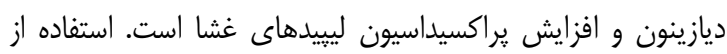

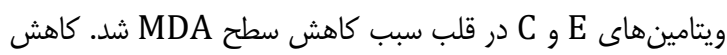
سطح MDA مىتواند مربوط به قابليت اين ويتامينها در حذف سابل

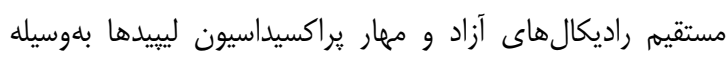

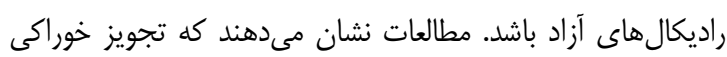

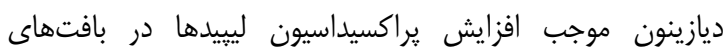

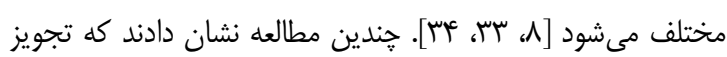

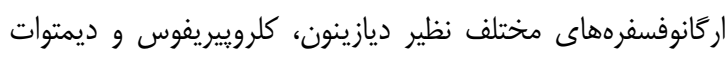

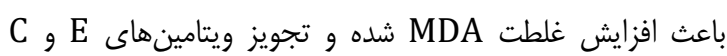

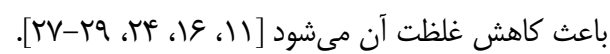

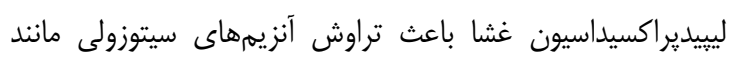

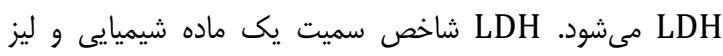

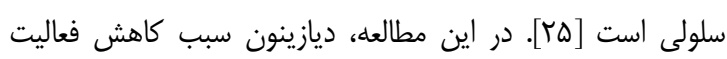
قلب شد كه تجويز ويتامينهاى CDH

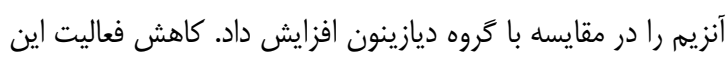

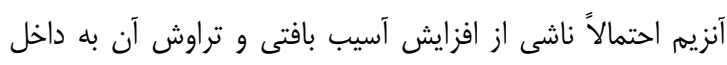

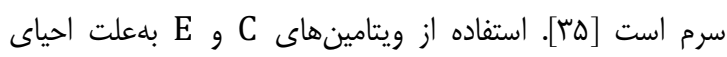

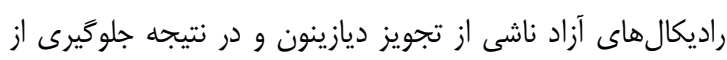

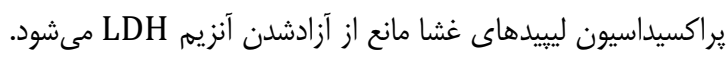

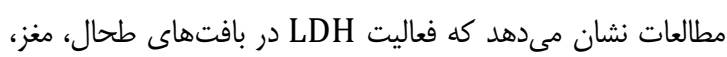

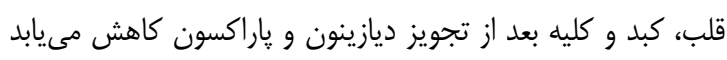

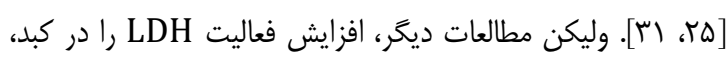

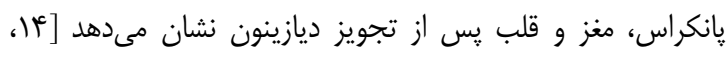

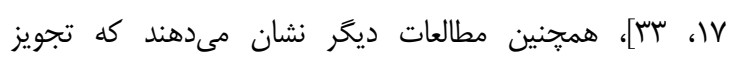
دى كلروس باعث افزايش فعاليت LDH و ايجاد استرس اكسيداتيو

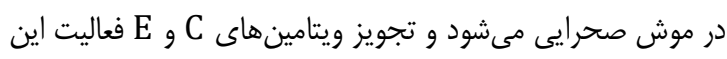

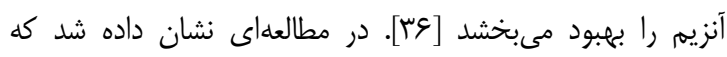

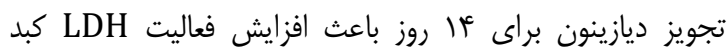

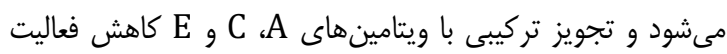

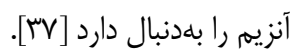

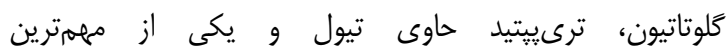

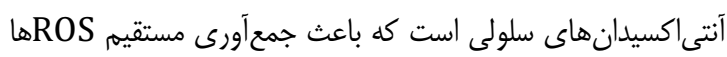

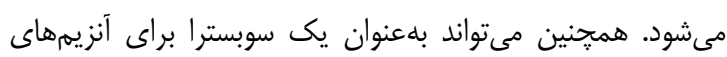

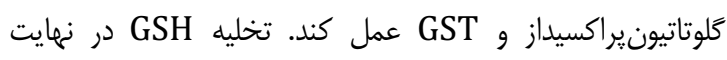

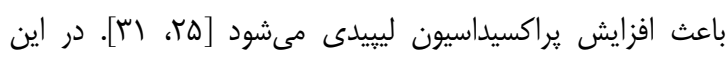

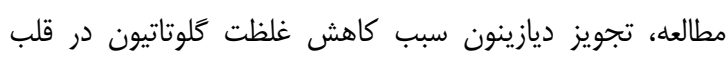

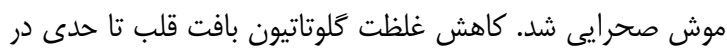

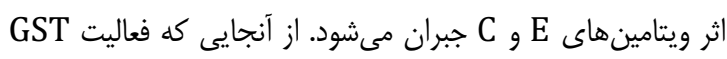

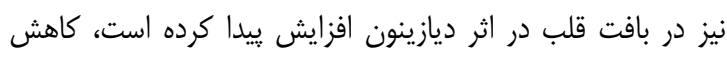


Clin Chim Acta. 1978;90(1):37-43.

22- Tietze F. Enzymic method for quantitative determination of nanogram amounts of total and oxidized glutathione: Applications to mammalian blood and other tissues. Anal Biochemistry. 1969;27(3):502-22. 23- Bradford MM. A rapid and sensitive method for the quantitation of microgram quantities of protein utilizing the principle of protein-dye binding. Anal Biochemistry. 1976;72:248-54.

24- Uzun FG, Kalender Y. Protective effect of vitamins C and $\mathrm{E}$ on malathion-induced nephrotoxicity in male rats. Gazi Univ J Sci. 2011;24(2):193-201.

25- Jafari M, Salehi M, Asgari A, Ahmadi S, Abbasnezhad M, Hajihoosani R, Hajigholamali M. Effects of paraoxon on serum biochemical parameters and oxidative stress induction in various tissues of wistar and norway rats. Environ Toxicol Pharmacol. 2012;34(3):876-7.

26- Abdallah FB, Gargouri B, Bejaoui H, Lassoued S, Ammar-Keskes L. Dimethoate-induced oxidative stress in human erythrocytes and the protective effect of vitamins $\mathrm{C}$ and $\mathrm{E}$ in vitro. Environ Toxicol. 2011;26(3):287-91.

27- Nisar NA, Mudasir Sultana, Waiz HA, Para PA, Baba NA, Zargar FA, Raja WH. Experimental study on the effect of vitamin $\mathrm{C}$ administration on lipid peroxidation and antioxidant enzyme activity in rats exposed to chlorpyriphos and lead acetate. Vet World. 2013;6(8):461-6

28- Al-Awthan YS, Al-Duais MA, El-Sokkary GH, Aqlan EM. Protective effects of vitamins $\mathrm{C}$ and $\mathrm{E}$ on dimethoateinduced nephrotoxicity in male guinea pigs. Annu Res Rev Biol. 2014;4(24):4023-33.

29- Saxena R, Garg P. Vitamin E provides protection against in vitro oxidative stress due to pesticide (Chlorpyrifos and Endosulfan) in goat RBC. GERF Bulletin Biosciences. 2010;1(1):1-6.

30- Astiz M, De Alaniz MJ, Marra CA. Antioxidant defense system in rats simultaneously intoxicated with agrochemicals. Environ Toxicol Pharmacol. 2009;28(3):465-73.

31- Jafari M, Salehi M, Ahmadi S, Asgari A, Abasnezhad M, Hajigholamali M. The role of oxidative stress in diazinoninduced tissues toxicity in wistar and norway rats. Toxicol Mech Methods. 2012;22(8):638-47.

32- Valavanidis A, Vlahogianni T, Dassenakis M, Scoullos M. Molecular biomarkers of oxidative stress in aquatic organisms in relation to toxic environmental pollutants. Ecotoxicology Environ Saf. 2006;64(2):178-89.

33- Abdou HM, ElMzoudy RH. Oxidative damage, hyperlipidemia and histological alterations of cardiac and skeletal muscles induced by different doses of diazinon in female rats. J Hazard Mater. 2010;182(13):273-8.

34- Leong CT, D'Souza UJ, Iqbal M, Mustapha ZA. Lipid peroxidation and decline in antioxidant status as one of the toxicity measures of diazinon in the testis. Redox Rep. 2013;18(4):155-64.

35- Salehi M, Jafari M, Saleh-Moqadam M, Asgari A. The comparison of the effect of diazinon and paraoxon on biomarkers of oxidative stress in rat serum. Zahedan J Res Med Sci. 2012;14(3):18-23.

36- Ogutcu A, Suludere Z, Kalender Y. Dichlorvosinduced hepatotoxicity in rats and the protective effects of vitamins $\mathrm{C}$ and E. Environ Toxicol Pharmacol. 2008;26(3):355-61.

37- Shokrzadeh M, Shobi S, Attar H, Shayegan S, Payam
11 إوس طهماسبى و همكاران

pesticides in a repeated dose study in rats. Rom J Morphol Embryol. 2013;54(2):349-56.

2- Bhatti GK, Sidhu IPS, Saini NK, Puar SK, Singh G, Bhatti JS. Ameliorative role of melatonin against cypermethrin induced hepatotoxicity and impaired antioxidant defense system in wistar rats. IOSR J Environ Sci Toxicol Food Technol. 2014;8(1):39-48.

3- Yassa VF, Girgis SM, Abumourad IMK. Potential protective effects of vitamin $\mathrm{E}$ on diazinon-induced DNA damage and some haematological and biochemical alterations in rats. J Mediterr Ecol. 2011;11:31-9.

4- Ahmadi S, Jafari M, Asgari AR, Salehi M. Acute effect of diazinon on the antioxidant system of rat's heart tissue.Trauma Monthly. 2011;16(2):87-93. [Persian]

5- Oruc E. Effects of diazinon on antioxidant defense system and lipid peroxidation in the liver of Cyprinus carpio (L.). Environ Toxicol. 2010; 26: 571-8.

6- Halliwell B. Free radicals and antioxidants: Updating a personal view. Nutr Rev. 2012;70(5):257-65.

7- Rafieian-Kopaei M, Baradaran A, Rafieian M. Oxidative stress and the paradoxical effects of antioxidants. J Res Med Sci. 2013;18(7):629.

8- Shah MD, Iqbal M. Diazinon-induced oxidative stress and renal dysfunction in rats. Food Chem Toxicol. 2010;48(12):3345-53.

9- Salehi M, Jafari M, Asgari AR, Ahmadi S. The role of paraoxon toxicity on oxidative stress induction in rat heart and spleen. Scientific J Zanjan Univ Med Sci. 2013;21(84):13-23. [Persian]

10- Abdel-Monem UM, Qar H, Attwa RA. Detoxification of dietary diazinon by clay, vitamin $\mathrm{C}$ and vitamin $\mathrm{E}$ in rabbits. World Appl Sci J. 2012;19(1):144-52.

11- Yilmaz N, Yilmaz M, Altuntas I. Diazinon-induced brain toxicity and protection by vitamins $\mathrm{E}$ plus C. Toxicol Ind Health. 2012;28(1):51-7.

12- Brigelius-Flohé R. Vitamin E and drug metabolism. Biochem Biophys Res Commun. 2003;305(3):737-40.

13- Duconge J, Miranda-Massari JR, Gonzalez MJ, Jackson JA, Warnock W, Riordan NH. Pharmacokinetics of vitamin $C$ : insights into the oral and intravenous administration of ascorbate. $\mathrm{P} R$ Health Sci J. 2008;27(1):7-19.

14- El-Shenawy NS, El-Salmy F, Al-Eisa RA, El-Ahmary B. Amelioratory effect of vitamin $\mathrm{E}$ on organophosphorus insecticide diazinon-induced oxidative stress in mice liver. Pestic Biochemistry Physiol. 2010;96(2):101-7.

15- Eroğlu S, Pandir D, Uzun FG, Bas H. Protective role of vitamins $C$ and $E$ in dichlorvos-induced oxidative stress in human erythrocytes in vitro. Biol Res. 2013;46(1):33-8. 16- Elzoghby RR, Hamoda AF, Abed-Ftah A, Farouk M. Protective role of vitamin $C$ and green tea extract on malathion-induced hepatotoxicity and nephrotoxicity in rats. Am J Pharmacol Toxicol. 2014;9(3):177-88.

17- Gokalp 0, Buyukvanlı B, Cicek E, Ozer MK, Koyu A, Altuntas I, et al. The effects of diazinon on pancreatic damage and ameliorating role of vitamin $\mathrm{E}$ and vitamin C. Pestic Biochemistry Physiol. 2005;81(2):123-8.

18- Winterbourn CC, Hawkins RE, Brian M, Carrell RW. The estimation of red cell superoxide dismutase activity. J Lab Clin Med. 1975;85(2):337-41.

19- Aebi H. Catalase in vitro. Methods Enzymol. 1984;105:121-6.

20- Habig WH, Jakoby WB. Glutathione S-transferases (rat and human). Methods Enzymol. 1981;77:218-31.

21- Satoh K. Serum lipid peroxide in cerebrovascular disorders determined by a new colorimetric method. 
ارزيابى شاخصهاى استرس اكسيداتيو در قلب موش صحرايى بعد از مواجهه با ديازينون و ويتامينهاى C و

Med Sci. 2012;16(1):1-9. [Persian]

39- Verma RS, Mehta A, Srivastava N. Comparative studies on chlorpyrifos and methyl parathion induced oxidative stress in different parts of rat brain: Attenuation by antioxidant vitamins. Pestic Biochemistry Physiol. 2009;95(3):152-8.

SS, Ghorbani F. Effect of vitamins A, E and C on liver enzyme activity in rats exposed to organophosphate pesticide diazinon. Pak J Biol Sci. 2012;15(19):936-41.

38- Ahmadi S, Jafari M, Asgari A, Salehi M. Acute effect of diazinon on lipid peroxidation level and activities of antioxidant enzymes in rat spleen. J Kermanshah Univ 